University of Wollongong

Research Online

Australian Institute for Innovative Materials -

Papers

Australian Institute for Innovative Materials

$1-1-2018$

\title{
A quadrafunctional electrocatalyst of nickel/nickel oxide embedded N- graphene for oxygen reduction, oxygen evolution, hydrogen evolution and hydrogen peroxide oxidation reactions
}

\author{
Shaikh N. Faisal \\ University of Wollongong, University of Sydney, shaikh@uow.edu.au \\ Md Enamul Haque \\ University of Sydney, enamul@uow.edu.au \\ Nikan Noorbehesht \\ University of Sydney \\ Hongwei Liu \\ University of Sydney \\ Md. Monirul Islam \\ University of Newcastle, mmi720@uowmail.edu.au
}

See next page for additional authors

Follow this and additional works at: https://ro.uow.edu.au/aiimpapers

Part of the Engineering Commons, and the Physical Sciences and Mathematics Commons

Research Online is the open access institutional repository for the University of Wollongong. For further information contact the UOW Library: research-pubs@uow.edu.au 


\title{
A quadrafunctional electrocatalyst of nickel/nickel oxide embedded $\mathrm{N}$-graphene for oxygen reduction, oxygen evolution, hydrogen evolution and hydrogen peroxide oxidation reactions
}

\author{
Abstract \\ A multifunctional nano-heterostructured electrocatalyst of transition metal/metal oxide (nickel/nickel \\ oxide) embedded on nitrogen-doped graphene is reported. The hybrid composite of N-doped graphene \\ nanosheets with a high atomic percentage of nitrogen (8.2 at\%) and embedded with highly distributed \\ nickel/nickel oxide nanoparticles inside the graphene layers is synthesized by a one pot thermal annealing \\ process. The resultant composite demonstrates excellent electrocatalytic activity utilizing the superior \\ electrocatalytic properties of nickel/nickel oxide nanoparticles supported on nitrogen-doped graphene. \\ The hybrid exhibits efficient oxygen reduction reaction (ORR) properties comparable with state-of-the-art \\ electrode $\mathrm{Pt} / \mathrm{C}$ with a four-electron transfer pathway and superior oxygen evolution reaction (OER) \\ compared to the state-of-the-art electrode for the OER, Ru/C. Alternatively, this composite acts as an \\ excellent electrode material for the hydrogen evolution reaction (HER) both in acidic and alkaline media. \\ Nevertheless, this composite facilitates the hydrogen peroxide oxidation reaction (HPOR) in the presence \\ of hydrogen peroxide, which is crucial for developing reversible fuel cells and fuel cells with liquid oxidant. \\ Disciplines \\ Engineering | Physical Sciences and Mathematics

\section{Publication Details} \\ Faisal, S. Nayeem., Haque, E., Noorbehesht, N., Liu, H., Shabnam, L., Roy, A., Pourazadi, E., Islam, M., Islam, \\ M., Harris, A. T. \& Minett, A. I. (2018). A quadrafunctional electrocatalyst of nickel/nickel oxide embedded \\ $\mathrm{N}$-graphene for oxygen reduction, oxygen evolution, hydrogen evolution and hydrogen peroxide oxidation \\ reactions. Sustainable Energy and Fuels, 2 (9), 2081-2089.

\section{Authors} \\ Shaikh N. Faisal, Md Enamul Haque, Nikan Noorbehesht, Hongwei Liu, Md. Monirul Islam, Luba Shabnam, \\ Anup Kumar Roy, Ehsan Pourazadi, Mohammod S. islam, Andrew T. Harris, and Andrew I. Minett
}




\section{Sustainable Energy \& Fuels}

We have presented the Graphical Abstract text and image for your article below. This brief summary of your work will appear in the contents pages of the issue in which your article appears.

1

\section{A quadrafunctional electrocatalyst of nickel/nickel oxide embedded $\mathrm{N}$-graphene for oxygen reduction, oxygen evolution, hydrogen evolution and hydrogen peroxide oxidation reactions}

Shaikh Nayeem Faisal, ${ }^{*}$ Enamul Haque, Nikan Noorbehesht, Hongwei Liu, Md. Monirul Islam, Luba Shabnam, Anup Kumar Roy, Ehsan Pourazadi, Mohammod S. Islam, Andrew T. Harris and Andrew I. Minett*

A multifunctional nano-heterostructured electrocatalyst of transition metal/metat oxide (nicket/nicket oxide) embeded 8 on nitrogen-doped graphene is reported.

Please check this proof carefully. Our staff will not read it in detail after you have returned it.

Proof corrections must be returned as a single set of corrections, approved by all co-authors. No further corrections can be made after you have submitted your proof corrections as we will publish your article online as soon as possible after they are received.

Please ensure that:

- The spelling and format of all author names and affiliations are checked carefully. Names will be indexed and cited as shown on the proof, so these must be correct.

- Any funding bodies have been acknowledged appropriately.

- All of the editor's queries are answered.

- Any necessary attachments, such as updated images or ESI files, are provided.

Translation errors between word-processor files and typesetting systems can occur so the whole proof needs to be read. Please pay particular attention to: tables; equations; numerical data; figures and graphics; and references.

Please send your corrections preferably as a copy of the proof PDF with electronic notes attached or alternatively as a list of corrections - do not change the text within the PDF file or send a revised manuscript. Corrections at this stage should be minor and not involve extensive changes.

Please return your final corrections, where possible within 48 hours of receipt, by e-mail to: sustainableenergy@arsc.org. If you require more time, please notify us by email. 
Providing accurate funding information will enable us to help you comply with your funders' reporting mandates. Clear acknowledgement of funder support is an important consideration in funding evaluation and can increase your chances of securing funding in the future. We work closely with Crossref to make your research discoverable through the Funding Data search tool (http://search.crossref.org/funding).

Further information on how to acknowledge your funders can be found on our webpage (http://rsc.li/funding-info).

\section{What is Funding Data?}

Funding Data (http://www.crossref.org/fundingdata/) provides a reliable way to track the impact of the work that funders support. We collect funding information from our authors and match this information to funders listed in the Crossref Funder Registry. Once an article has been matched to its funders, it is discoverable through Crossref's search interface.

\section{PubMed Central}

Accurate funder information will also help us identify articles that are mandated to be deposited in PubMed Central (PMC) and deposit these on your behalf.

\section{Providing funder information}

We have combined the information you gave us on submission with the information in your acknowledgements.

This will help ensure funding information is as complete as possible and matches funders listed in the Crossref

Funder Registry. Please check that the funder names and grant numbers in the table are correct. This table will not be included in your final PDF but we will share the data with Crossref so that your article can be found via the Funding Data search tool.

\begin{tabular}{|l|l|l|}
\hline Funder name & Funder ID (for RSC use only) & Award/grant/contract number \\
\hline University of Sydney & 501100001774 & Unassigned \\
\hline
\end{tabular}

If a funding organisation you included in your acknowledgements or on submission of your article is not currently listed in the registry it will not appear in the table above. We can only deposit data if funders are already listed in the Crossref Funder Registry, but we will pass all funding information on to Crossref so that additional funders can be included in future.

\section{Researcher information}

If any authors have ORCID or ResearcherID details that are not listed below, please provide these with your proof corrections.

Please check that the ORCID and ResearcherID details listed below have been assigned to the correct author.

Authors should have their own unique ORCID iD and should not use another researcher's, as errors will delay publication.

Please also update your account on our online manuscript submission system to add your ORCID details, which will then be automatically included in all future submissions. See here for step-by-step instructions and more information on author identifiers.

\begin{tabular}{|l|l|l|l|}
\hline First (given) name(s) & Last (family) name(s) & ResearcherID & ORCID \\
\hline Shaikh Nayeem & Faisal & & 0000-0003-3317-2282 \\
\hline Enamul & Haque & & \\
\hline Nikan & Noorbehesht & & \\
\hline Hongwei & Liu & & \\
\hline Md. Monirul & Islam & & \\
\hline
\end{tabular}




\begin{tabular}{l|l|l|l|l|}
1 & Luba & Shabnam & & \\
\cline { 2 - 5 } & Anup Kumar & Roy & & \\
\cline { 2 - 5 } 5 & Ehsan & Pourazadi & & \\
\cline { 2 - 5 } & Mohammod S. & Islam & & \\
\hline & Andrew T. & Harris & & \\
\hline Andrew I. & Minett & & \\
\hline
\end{tabular}




\section{Journal: Sustainable Energy \& Fuels}

5 Paper: c8se00068a

Title: A quadrafunctional electrocatalyst of nickel/nickel oxide embedded $\mathrm{N}$-graphene for oxygen reduction, oxygen evolution, hydrogen evolution and hydrogen peroxide oxidation reactions

For your information: You can cite this article before you receive notification of the page numbers by using the following format: (authors), Sustainable Energy Fuels, (year), DOI: 10.1039/c8se00068a.

Editor's queries are marked on your proof like this 1, 2, etc. and for your convenience line numbers are indicated like this $5,10,15$,

Please ensure that all queries are answered when returning your proof corrections so that publication of your article is not delayed.

\begin{tabular}{|c|c|c|}
\hline $\begin{array}{l}\text { Query } \\
\text { Reference }\end{array}$ & Query & Remarks \\
\hline 1 & $\begin{array}{l}\text { Funder details have been incorporated in the funder table using } \\
\text { information provided in the article text. Please check that the } \\
\text { funder information in the table is correct. }\end{array}$ & \\
\hline 2 & $\begin{array}{l}\text { Please confirm that the spelling and format of all author names is } \\
\text { correct. Names will be indexed and cited as shown on the proof, } \\
\text { so these must be correct. No late corrections can be made. }\end{array}$ & \\
\hline 3 & $\begin{array}{l}\text { Please check that the inserted Graphical Abstract image is } \\
\text { suitable. }\end{array}$ & \\
\hline 4 & $\begin{array}{l}\text { The sentence beginning "Alternative multifunctional..." has been } \\
\text { altered for clarity. Please check that the meaning is correct. }\end{array}$ & \\
\hline 5 & $\begin{array}{l}\text { The sentence beginning "Taking into..." has been altered for } \\
\text { clarity. Please check that the meaning is correct. }\end{array}$ & \\
\hline 6 & $\begin{array}{l}\text { The sentence beginning "The resulting..." has been altered for } \\
\text { clarity. Please check that the meaning is correct. }\end{array}$ & \\
\hline 7 & $\begin{array}{l}\text { The meaning of the sentence beginning "The interaction..." is not } \\
\text { clear - please provide alternative text. }\end{array}$ & \\
\hline 8 & $\begin{array}{l}\text { The first line of the Abstract has been inserted as the Graphical } \\
\text { Abstract text. Please check that this is suitable. If the text does not } \\
\text { fit within the two horizontal lines, please trim the text and/or the } \\
\text { title. }\end{array}$ & \\
\hline
\end{tabular}


Cite this: DOI: $10.1039 / \mathrm{c} 8 \mathrm{se} 00068 \mathrm{a}$

\section{A quadrafunctional electrocatalyst of nickel/nickel oxide embedded $\mathrm{N}$-graphene for oxygen reduction, oxygen evolution, hydrogen evolution and hydrogen peroxide oxidation reactions $\uparrow$}

Shaikh Nayeem Faisal, (D) *af Enamul Haque, ${ }^{a}$ Nikan Noorbehesht, ${ }^{a}$ Hongwei Liu, ${ }^{b}$ Md. Monirul Islam, ${ }^{c}$ Luba Shabnam, ${ }^{a}$ Anup Kumar Roy, ${ }^{a}$ Ehsan Pourazadi, ${ }^{d}$ Mohammod S. Islam, ${ }^{e}$ Andrew T. Harris ${ }^{a}$ and Andrew I. Minett ${ }^{* a}$

A multifunctional nano-heterostructured electrocatalyst of transition metal/metal oxide (nickel/nickel oxide) embedded on nitrogen-doped graphene is reported. The hybrid composite of $\mathrm{N}$-doped graphene nanosheets with a high atomic percentage of nitrogen (8.2 at\%) and embedded with highly distributed nickel/nickel oxide nanoparticles inside the graphene layers is synthesized by a one pot thermal annealing process. The resultant composite demonstrates excellent electrocatalytic activity utilizing the superior electrocatalytic properties of nickel/nickel oxide nanoparticles supported on nitrogen-doped graphene. The hybrid exhibits efficient oxygen reduction reaction (ORR) properties comparable with state-of-the-art electrode $\mathrm{Pt} / \mathrm{C}$ with a four-electron transfer pathway and superior oxygen evolution reaction (OER) compared to the state-of-the-art electrode for the OER, Ru/C. Alternatively, this composite acts as an excellent electrode material for the hydrogen evolution reaction (HER) both in acidic and alkaline media. Nevertheless, this composite facilitates the hydrogen peroxide oxidation reaction (HPOR) in the presence of hydrogen peroxide, which is crucial for developing reversible fuel cells and fuel cells with liquid oxidant.

not only scarce and expensive but also get poisoned easily and do not exhibit similar performance for both the oxygen reduction and oxygen evolution reactions., ${ }^{2,45}$ Alternative multifunctional nonprecious electrode materials with multiple electrocatalytic properties are highly essential to overcome these limitations. ${ }^{5,6}$ Chemically doped carbon nanostructured materials have been demonstrated to exhibit remarkable electrocatalytic properties, making them a promising alternative to noble metals. ${ }^{2,7-10}$ Among the different types of chemically doped carbon, two-dimensional carbon materials, in particular chemically doped graphene, have drawn widespread attention due to their extraordinary electrochemical properties achieved by introducing active sites for electrocatalysis. ${ }^{9}$ Different heteroatoms (N, B, P, and S) have been utilized for doping in the carbon lattice and from this class of doped material, nitrogen doped carbon and graphene showed superior performance both for the ORR and OER. ${ }^{\text {7,9,11 }}$ Further modification of nitrogendoped graphene by dual doping or incorporating nonprecious metal nanoparticles can enhance its performance for the ORR and OER, making it comparable to that of noble metal electrodes. ${ }^{\mathbf{1 2 - 1 5}}$ In dual doping, $\mathrm{N}$ and $\mathrm{P}$ have recently attracted a lot of interest because of the enhancement of the bifunctional metal-free electrocatalytic activity by increasing active sites with surface area. ${ }^{14,15}$ However, the restacking nature of graphene Engineering, The University of Sydney, NSW 2006, Australia. E-mail: shaikh.faisal@ sydney.edu.au; andrew.minett@sydney.edu.au

2006, Australia

'School of Environmental \& Life Sciences, University of Newcastle, Callaghan, NSW2308, Australia

${ }^{d}$ Department of Chemical \& Process Engineering, The University of Canterbury, Christchurch, New Zealand

${ }^{e}$ School of Mechanical \& Manufacturing Engineering, University of New South Wales, NSW 2052, Australia

${ }^{f}$ ARC Centre of Excellence for Electromaterials Science, AIIM Facility, University of Wollongong, Wollongong, NSW-2522, Australia

$\dagger$ Electronic supplementary information (ESI) available. See DOI: $10.1039 / \mathrm{c} 8 \mathrm{se} 00068 \mathrm{a}$ 
1 can reduce the active electrochemical surface area and thus hinder its properties for practical applications. ${ }^{16}$ The decoration of graphene layers with a nonprecious metal catalyst can provide a three-dimensional structure with a high electroactive surface area as well as synergistic electrocatalytic activity with the conjugation of the metal catalyst. ${ }^{12,13,17}$ Transition metal nanoparticles, in particular nickel and cobalt, demonstrate efficient electrocatalytic activity towards the ORR, OER and HER; however pure cobalt, nickel and nickel oxides generally show insufficient electrical conductivity and limited kinetics for electrocatalysis of the ORR, OER and HER. ${ }^{6,17-19}$ The combination of $\mathrm{N}-\mathrm{Gr}$ with transition metal nanoparticles can be an effective way to improve the active electrochemical properties, and the atomic percentage of metal doping on the graphene lattice can play a role in single atom catalysis. ${ }^{17,20-22}$ Even though the hybrid of cobalt nanoparticles with nitrogen-doped graphene demonstrated superior ORR and HER performance, ${ }^{\mathbf{2 0 , 2 1}}$ the combination of nickel nanoparticles with nitrogen doped graphene can improve the electrocatalytic activity of the composite for the OER, HER and hydrogen oxidation reaction (HOR) due to the high affinity of nickel towards hydrogen adsorption and the active sites for the OER. ${ }^{23-27}$ The reported nickel confined N-Gr showed good OER properties; however the synthesis procedures required several steps and the ORR properties were not mentioned..$^{27}$ Alternatively, the hybrid of $\mathrm{Ni}$ / $\mathrm{NiO}$ with $\mathrm{N}-\mathrm{Gr}$ synthesized via pyrolysis followed by hydrothermal treatment in multiple steps demonstrated efficient OER and HER performance; however, the ORR performance of the composite was not efficient. ${ }^{20}$

Herein we report a single-step synthesis of nickel/nickel oxide nanoparticle embedded nitrogen doped graphene with multifunctional electrocatalytic properties via thermal annealing. The synthesis procedure is performed by thermal annealing of the mixture of graphene oxide, nickel nitrate and uric acid as a solid precursor of nitrogen at $800{ }^{\circ} \mathrm{C}$ under an argon atmosphere. Uric acid has a high nitrogen content ( $\sim 33 \mathrm{wt} \%)$, and its crystals can adhere to surfaces bearing various organic functionalities via multiple types of forces (electrostatic interactions, hydrogen bonding and/or van der Waals interactions), without

5 the aid of surfactants. ${ }^{28}$ Taking into account its properties, a nanocomposite of nickel/nickel oxide embedded nitrogendoped reduced graphene oxide ( $\mathrm{Ni} / \mathrm{NGr})$ was synthesized via co-pyrolysis of graphene oxide and uric acid with nickel nitrate. The synthesized nanocomposite contains a high atomic percentage of nitrogen doping in all of the possible configurations and three dimensional structures for insertion of nickel nanoparticles all over the graphene lattice in different dimensions. As a result, the nickel/nickel oxide/N-doped graphene nanocomposite exhibits high electrocatalytic activity for the ORR, OER, HER and HPOR due to the active sites as well as three-dimensional structure.

\section{Experimental}

\section{Synthesis of nickel/nickel oxide/N-doped graphene}

GO was prepared from naturally expanded graphite (Ashbury Carbons, Grade-3772) using a procedure reported for the generation of ultra-large GO sheets. ${ }^{28}$ The GO sheets (approx. 20 $\mathrm{mg}$ ) were dispersed in water by ultrasonication for $30 \mathrm{~min}$ at a frequency of $50 \mathrm{~Hz}$, and then mixed with uric acid and nickel nitrate in a ratio of $1: 5: 0.5$ by mass. The mixtures were then stirred continuously and heated at $80{ }^{\circ} \mathrm{C}$ for $10-12 \mathrm{~h}$ to remove the water. The resulting solids were transferred to a tube furnace and heated in an argon atmosphere at $5{ }^{\circ} \mathrm{C} \min ^{-1}$ to $800{ }^{\circ} \mathrm{C}$, and then annealed for $1 \mathrm{~h}$. The synthesized nitrogendoped graphene with nickel nanoparticles was named Ni/NGr. GO mixed with uric acid in the same ratio (1:5) without nickel nitrate was also thermally annealed to yield nitrogendoped graphene named NGr. GO mixed with nickel salt in the absence of uric acid in the ratio of $1: 0.5$ under the same conditions was named $\mathrm{Ni} / \mathrm{Gr}$ and used as a reference.

\section{Characterization}

The microstructures and morphology of the synthesized samples were investigated by Field Emission Scanning Electron Microscopy (FESEM, Zeiss ULTRA Plus) and High Resolution Transmission Electron Microscopy (HRTEM, JEOL 2200FS) with an acceleration voltage of $200 \mathrm{kV}$. X-ray diffractometry (XRD) was performed on a Shimadzu $\mathrm{S} 6000$ equipped with $\mathrm{Cu} \mathrm{K} \alpha$ radiation $(\lambda=0.154 \mathrm{~nm})$ with a resolution of $0.02^{\circ}$. Raman spectra were collected with a Renishaw inVia Raman Spectrometer with a laser wavelength of $514 \mathrm{~nm}$. X-ray photoelectron spectroscopy (XPS) analyses were performed using an ESCALAB250Xi (Thermo Scientific, UK) with a monochromated $\mathrm{Al} \mathrm{K \alpha}$ (energy $1486.68 \mathrm{eV}$ ) source operating at $150 \mathrm{~W}(13 \mathrm{kV} \times 12 \mathrm{~mA})$ under a vacuum of $2 \times 10^{-9} \mathrm{mbar}$. The analysis spot was 500 $\mu \mathrm{m}$ in diameter. The binding energies were referenced to the adventitious hydrocarbon C 1s signal at $284.9 \mathrm{eV}$.

\section{Electrochemical measurements}

For electrochemical characterization and measurements, $\mathrm{Ni}$ / $\mathrm{NGr}, \mathrm{Ni} / \mathrm{Gr}$ and $\mathrm{NGr}$ were deposited from a $1 \mathrm{mg} \mathrm{mL} \mathrm{m}^{-1}$ mixture, prepared by sonication in degassed isopropanol, on a glassy-carbon electrode. The glassy-carbon working electrode was polished mechanically with a slurry of $0.05 \mu \mathrm{m}$ alumina particles to obtain a mirror-like surface, washed with Milli-Q water and acetone, and allowed to dry. It was then tested in a three-electrode cell, using platinum wire as the counter electrode and a $\mathrm{Ag} / \mathrm{AgCl}, \mathrm{KCl}(3 \mathrm{M})$ electrode as the reference electrode. Measurements were taken using a Bio-Logic SP300 potentiostat. The binding agent was $0.5 \mathrm{wt} \%$ Nafion for electrocatalytic measurements.

The electrocatalytic properties were evaluated by rotating disk electrode (RDE) experiments in an $\mathrm{O}_{2}$-saturated $0.1 \mathrm{M} \mathrm{KOH}$ solution. First, the oxygen-reduction capability was assessed by comparing cyclic voltammetric curves measured in argon- and oxygen-saturated electrolytes. Linear sweep voltammetry curves were recorded over the potential range of 0.0 to $-0.8 \mathrm{~V}$ at a scan rate of $10 \mathrm{mV} \mathrm{s}^{-1}$ at ambient temperature and at rotation speeds of 100-2000 rpm. OER activity was measured by linear sweep voltammetry in the potential window ranging from 1.0 to $1.8 \mathrm{~V}$ versus the reversible hydrogen electrode (RHE) scale by adding a value of $0.964 \mathrm{~V}$. The HER activity was investigated in $0.1 \mathrm{M}$ 
$\mathrm{KOH}$ and $0.1 \mathrm{M} \mathrm{H}_{2} \mathrm{SO}_{4}$ solution and the HOR properties were evaluated in $0.1 \mathrm{M} \mathrm{NaOH}$ electrolyte in the presence of hydrogen peroxide solution. Commercial $\mathrm{Pt} / \mathrm{C}(20 \mathrm{wt} \%)$ and $\mathrm{Ru} / \mathrm{C}$ (20 wt\%) in Nafion solution with the same loading amount were taken for comparison.

\section{Results and discussion}

In the single pot synthesis of nickel nanoparticles embedded in nitrogen-doped graphene (Scheme 1), graphene oxide, uric acid and nickel nitrate were mixed together in water (in a ratio of $1: 5: 0.5$ by mass at the $\mathrm{mg}$ scale), and then stirred continuously at $80^{\circ} \mathrm{C}$ to remove the water. The nickel nitrate salt and uric acid dispersed and adsorbed on the graphene oxide surface during the mixing. Uric acid has been reported as a solid nitrogen precursor which can be doped in the graphene lattice with a high atomic percentage of $\mathrm{N}$ in all the possible configurations. ${ }^{28}$ The nickel salt was reduced at high temperature to form nickel/nickel oxide nanoparticles. The oxygen groups in graphene oxide and uric acid contributed to form nickel oxide along with nickel nanoparticles on the graphene surface.

The morphology, structure and graphitic layers of the obtained $\mathrm{Ni} / \mathrm{NGr}$ were characterized by scanning electron microscopy (SEM) and transmission electron microscopy (TEM). The SEM images of $\mathrm{Ni} / \mathrm{NGr}$ showed a laminar morphology of graphene and the nanoparticles of nickel of approximately $50 \mathrm{~nm}$ are easily visible situated on the edges as well as inside the graphene layers (Fig. 1a). To further characterize the surface of the nanocomposite, a low-magnification TEM image was obtained and it showed highly distributed nickel and nickel oxide nanoparticles embedded in the transparent stacked graphene sheets in the range of 5 to $50 \mathrm{~nm}$ (Fig. 1b). To investigate the proper distribution of nickel nanoparticles on the graphene sheet, high-angle annular dark field (HAADF) STEM was applied. The bright-field STEM image shows the distribution of nickel nanoparticles on the graphene sheet in the $5-50 \mathrm{~nm}$ range and the small particles are embedded into the graphene layers (Fig. 1c). The corresponding

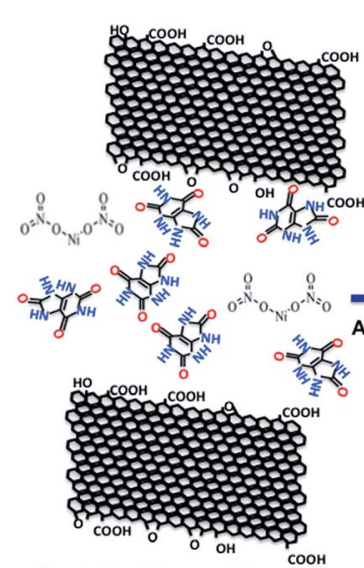

Single Pot Mixture of Graphene Oxide, Uric Acid and Nickel Nitrate
Nickel Nanoparticles Embedded N-Gr as Quadrafunctional Electrocatalyst

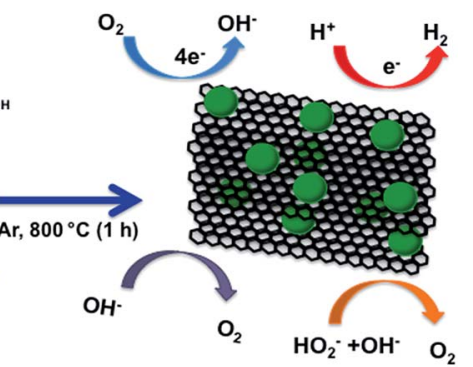

Scheme 1 Schematic diagram of the formation of Ni/NGr via the thermal annealing of graphene oxide with uric acid and nickel nitrate.
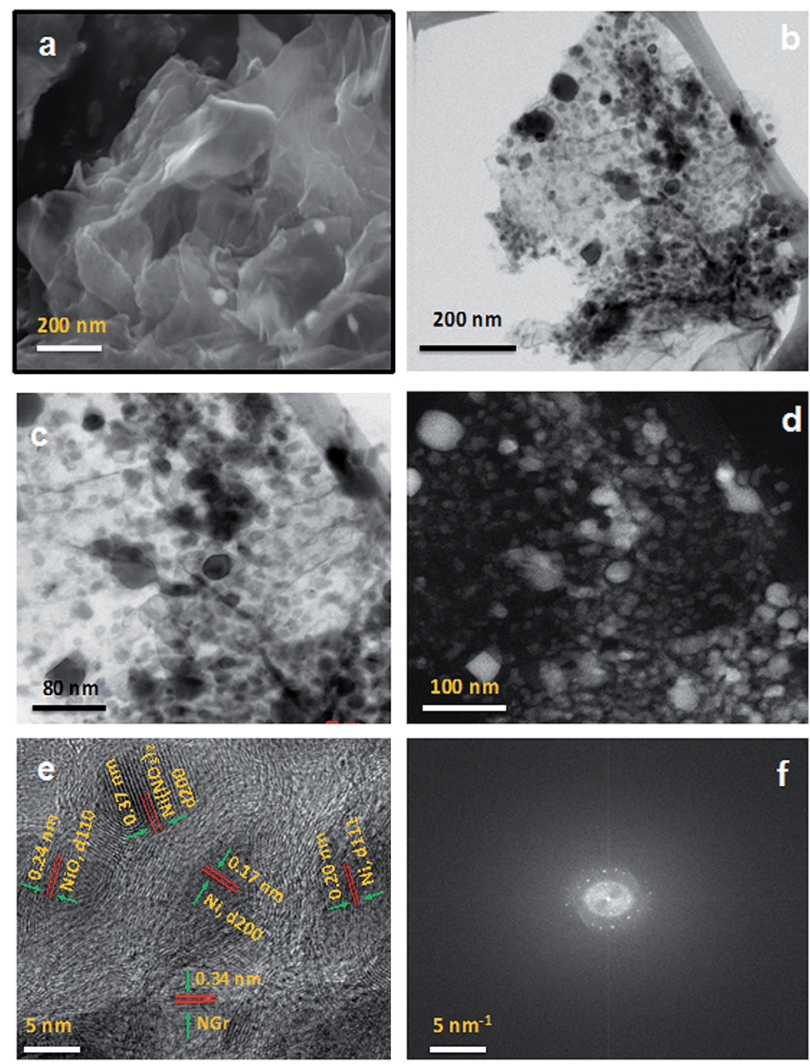

Fig. 1 (a) SEM image of Ni/NGr, (b) TEM image of Ni/NGr, (c) brightfield STEM image of Ni/NGr, (d) HAADF-STEM image showing highly distributed nickel nanoparticles on graphene, (e) HRTEM image showing lattices of nickel and nickel oxide nanoparticles embedded into the graphene lattice and (f) the corresponding FFT image of Ni/ $\mathrm{NGr}$ showing adjacent nickel atoms with the hexagonal graphene pattern

HAADF image (Fig. 1d) clearly shows the bright spots of nanoparticles well dispersed in the carbon matrix. The highresolution transmission electron micrograph (HRTEM) combined with STEM-EDS clearly verifies the formation of nanoparticles onto graphene sheets (Fig. 1e). The lattice fringes with widths of 2.0 and $1.7 \AA$ are assigned to the (111) and (200) crystal planes of fcc structures of pure Ni respectively and the lattice fringes with a width of $2.4 \AA$ are assigned to the (110) crystal planes of $\mathrm{NiO}^{29}$ The lattice fringes with a width of $3.4 \AA$ are the crystal planes of NGr. Interestingly, different crystal planes of the lattice fringes with a width of $3.7 \AA$ are observed, which are close to the (200) crystal planes of $\mathrm{Ni}\left(\mathrm{NO}_{3}\right)_{2} \cdot{ }^{30}$ The presence of nanometer sized $\mathrm{Ni}\left(\mathrm{NO}_{3}\right)_{2}$ can provide insight into the formation mechanism of nickel and nickel nitrate nanoparticles by thermal annealing of nickel nitrate salt supported by graphene layers. During the annealing, the salt becomes encapsulated inside the graphene layers and starts reducing at high temperature to form nanostructured nickel and nickel oxides; however, a small portion remains unreacted for encapsulation inside the graphene layers and forms the (200) crystal planes of nickel nitrate nanoparticles. The corresponding fast Fourier transformation (FFT) image revealed the highly 
crystalline nature of the composite (Fig. 1f). The FFT image is similar to the electron diffraction pattern with the difference of the investigated area size and the way of producing it. The welldefined diffraction spots and rings in the FFT image confirmed that the sample was comprised of a hexagonal carbon lattice typical of graphene-like materials and a comparatively bigger spot of nickel was clearly identified adjacent to the hexagonal carbon lattice. The STEM-EDS mapping provided further confirmation and the elemental distribution of Ni/NGr (Fig. 2). The distribution of carbon, nitrogen and nickel (Fig. 2b-e) demonstrated the dominant metallic Ni with nitrogen on the carbon. Based on the STEM images, the regular distribution of nickel nanoparticles embedded on nitrogen-doped graphene layers was clearly visible. The presence of some oxygen on nickel in the EDS-mapping (Fig. 2f) indicates the formation of nickel oxide along with nickel nanoparticles. The overall mapping of all the elements (Fig. 2f) shows the position of the elements and the presence of nickel and nickel oxide particles on the graphene layers. The TEM-EDS elemental line profile further confirms the presence of $\mathrm{C}, \mathrm{O}, \mathrm{N}$ and $\mathrm{Ni}$ on the surface (Fig. S3 and $\mathrm{S} 4 \dagger$ ).

The XRD patterns of Ni/NGr and NGr (Fig. 3a) indicated a slight shifting of the graphene peak corresponding to $\mathrm{Ni} / \mathrm{NGr}$ at around $24.0^{\circ}$ from the graphene peak of NGr at $26.5^{\circ}$, which corresponded to an interlayer spacing $0.370 \mathrm{~nm}$ larger than the usual interlayer spacing of $\mathrm{NGr}(0.33 \mathrm{~nm})$ calculated at $27^{\circ}$ due to the encapsulation of nickel nanoparticles inside the graphene layers which alters the interlayer spacing. The peak of $\mathrm{Ni}$ /
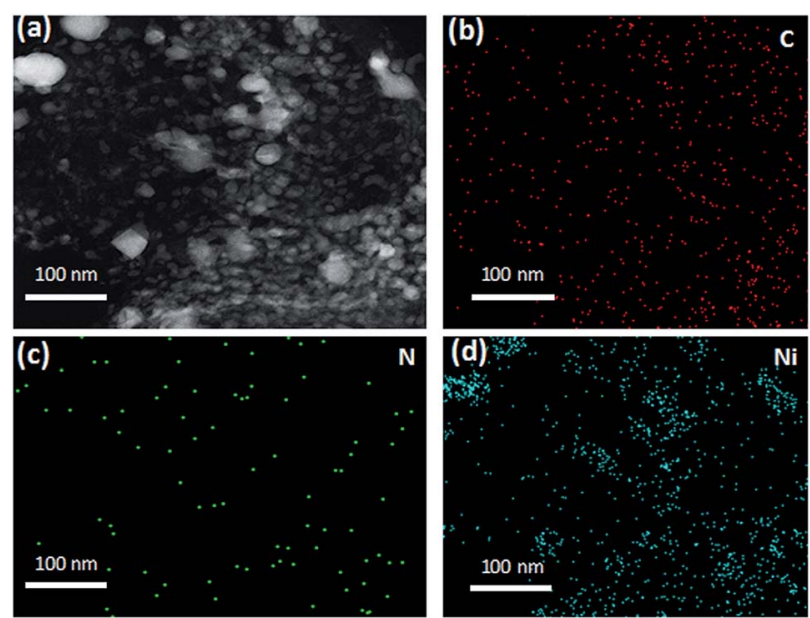

50
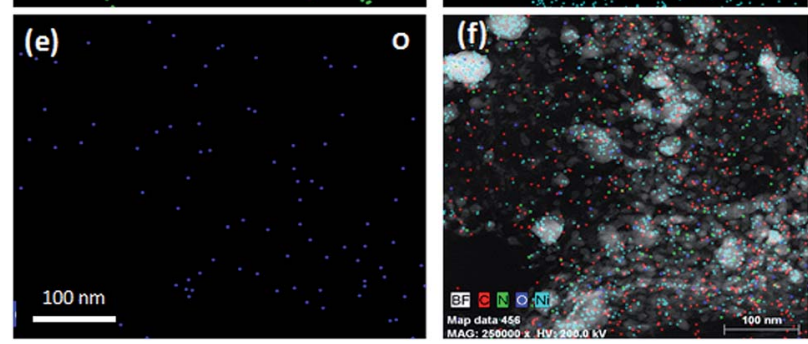

Fig. 2 (a) Enlarged selected area for STEM-EDS mapping, (b) STEMEDS mapping of $C$, (c) STEM-EDS mapping of $N$, (d) STEM-EDS mapping of $\mathrm{Ni}$, (e) STEM-EDS mapping of $\mathrm{O}$, and (f) STEM-EDS mapping of all of these elements.
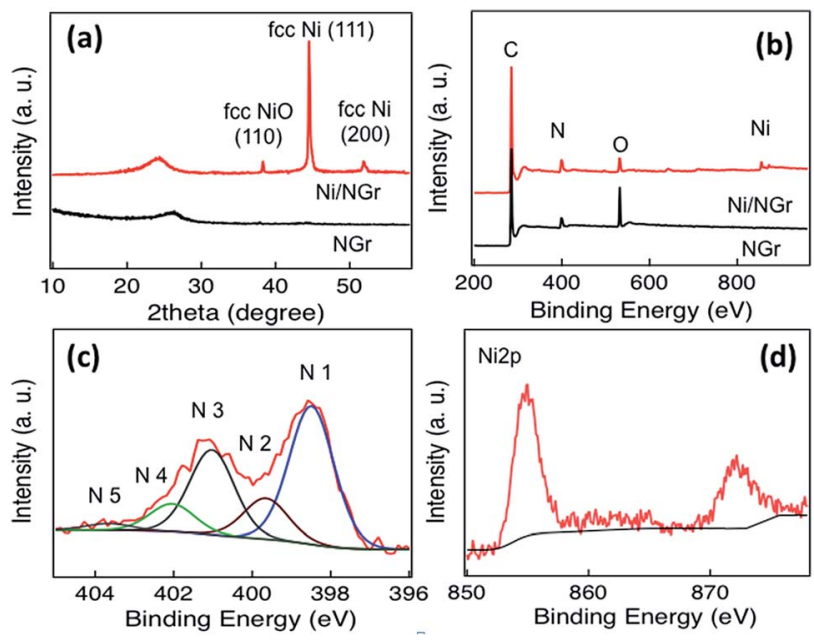

10

Fig. 3 (a) XRD patterns of Ni/NGr and NGr, (b) XPS survey spectra of $\mathrm{Ni} / \mathrm{NGr}$ and NGr, (c) N 1s XPS spectrum of Ni/NGr and (d) Ni 2p XPS spectrum of $\mathrm{Ni} / \mathrm{NGr}$.

NGr at 38.4, 44.5 and $51.8^{\circ}$ belong to fcc NiO (110), fcc Ni (111) and fcc Ni (200) respectively, which matched with the crystal structure calculated from the HRTEM image (Fig. 1e). The XRD pattern of Ni/Gr was also compared to Ni/NGr (Fig. S7 $\dagger$ ). From the comparison it was observed that the graphene peak of $\mathrm{Ni} / \mathrm{Gr}$ is situated at $27^{\circ}$, similar to NGr with an interlayer spacing of $0.33 \mathrm{~nm}$. Here, uric acid functioned as the carbon skeleton preventing the nickel nanoparticles from agglomerating and instead causing them to distribute uniformly in the graphene layer during the annealing process at high temperature. ${ }^{31}$ The presence of $\mathrm{NiO}$ nanoparticles with $\mathrm{Ni}$ nanoparticles in both of the composites of $\mathrm{Ni} / \mathrm{NGr}$ and $\mathrm{Ni} / \mathrm{Gr}$ was confirmed from the XRD pattern; however the fcc Ni (111) dominates in the Ni/Gr sample. The Ni/NGr and NGr samples were further characterized by Raman spectroscopy at an excitation wavelength of $514 \mathrm{~nm}$ under ambient conditions. As shown in Fig. S6 $†$ the $\mathrm{G}$ peaks of Ni/NGr, Ni/Gr and NGr occurred between 1582 and $1598 \mathrm{~cm}^{-1}$ indicating defect formation due to nitrogen doping as well as thermal treatment. The broad peak at $518 \mathrm{~cm}^{-1}$ in Ni/ NG and Ni/Gr confirms the presence of nickel oxide on the surface, which was absent in NGr.

To characterize the elemental composition and nitrogen content in the Ni/NGr and NGr samples, X-ray photoelectron spectra (XPS) of the materials were measured. A comparison of the spectra of Ni/NGr and NGr showed an increment of nitrogen content in Ni/NGr due to the contribution of nitrogen in the nickel salt and an obvious $\mathrm{Ni} 2 \mathrm{p}$ peak for nickel and nickel oxide (Fig. 3b). The deconvolution of the $\mathrm{N}$ 1s peaks (Fig. 3c) showed the presence of five nitrogen configurations. Both Ni/NGr and NGr contained primarily $(>40 \%)$ pyridinic nitrogen, $\sim 15 \%$ pyrrolic N, 35\% graphitic $\mathrm{N}$ and minor amounts $(<10 \%)$ of $\mathrm{N}$ oxides and pyridinic $\mathrm{N}-\mathrm{H}$. The total nitrogen content in $\mathrm{Ni}$ / NGr was 8.1 at\%, and in NGr it was 7.6 at\%. The efficient doping of nickel (0.56 at\%) as Ni 2p spectra arising from the multi-electron excitation in the main peak along with the satellite peak in the $\mathrm{Ni} 2 \mathrm{p}$ core-level spectra was observed 
(Fig. 3d). The deconvolution of the $\mathrm{Ni} 2 \mathrm{p}_{3 / 2}$ peak of Ni/NGr (Fig. S8 $\dagger$ ) showed peaks at around $854.7 \mathrm{eV}, 855.9 \mathrm{eV}$ and $860.8 \mathrm{eV}$ corresponding to $\mathrm{NiO}, \mathrm{NiOOH}$ and $\beta-\mathrm{Ni}(\mathrm{OH})_{2}$, respectively. ${ }^{32-34}$ The peak formed at $864.8 \mathrm{eV}$ was the satellite peak of $\mathrm{NiO}^{34}$ The $\mathrm{Ni} 2 \mathrm{p}_{3 / 2}$ spectra of $\mathrm{Ni} / \mathrm{Gr}$ indicated the presence of metallic nickel from the peak at around $852.9 \mathrm{eV}$, the $\mathrm{NiOOH}$ peak at $855.7 \mathrm{eV}$, the $\beta-\mathrm{Ni}(\mathrm{OH})_{2}$ peak at $860.3 \mathrm{eV}$ and the satellite peak of Ni 2p at $863.9 \mathrm{eV}$ (Fig. S9†). The XPS peak at $854.7 \mathrm{eV}$ corresponding to $\mathrm{NiO}$ was absent in $\mathrm{Ni} / \mathrm{Gr}$.

The thermogravimetric analysis curves of $\mathrm{Ni} / \mathrm{Gr}$ and $\mathrm{Ni} / \mathrm{NGr}$ (Fig. S10 \& S11 $\dagger$ ) provide the weight percentages of the nickel/ nickel oxide in the composites. From the thermogravimetric analysis (TGA) it was measured that both of the composites contain around $40 \mathrm{wt} \%$ of nickel. In addition, the decomposition behaviour of $\mathrm{Ni} / \mathrm{Gr}$ showed rapid weight loss after $700{ }^{\circ} \mathrm{C}$ for removal of oxygen groups whereas the Ni/NGr showed stepby-step weight loss for decomposition of uric acid and deoxygenation.

\section{Electrocatalytic activity towards the oxygen reduction reaction (ORR)}

The electrocatalytic activity of $\mathrm{Ni} / \mathrm{NGr}$ as an electrocatalyst is evaluated for the oxygen reduction reaction (ORR) under alkaline conditions. The electrocatalytic activities are investigated using rotating disk electrodes (RDEs). Fig. 4a shows the linear sweep voltammograms of $\mathrm{Ni} / \mathrm{NGr}$ at different rotation frequencies, all measured at a scan rate of $10 \mathrm{mV} \mathrm{s}^{-1}$ in oxygensaturated $0.1 \mathrm{M} \mathrm{KOH}(\mathrm{aq})$. Ni/NGr produced a positive onset potential of $+0.82 \mathrm{~V}$ and a highest current density of $-5.0 \mathrm{~mA}$ $\mathrm{cm}^{-2}$ at a rotation frequency of $2000 \mathrm{rpm}$. Further RDE measurements (Fig. 6b) were thus used to calculate, using the Koutecky-Levich equation (eqn (1)), ${ }^{20}$ the number of electrons transferred to an oxygen molecule by the Ni/NGr electrode.
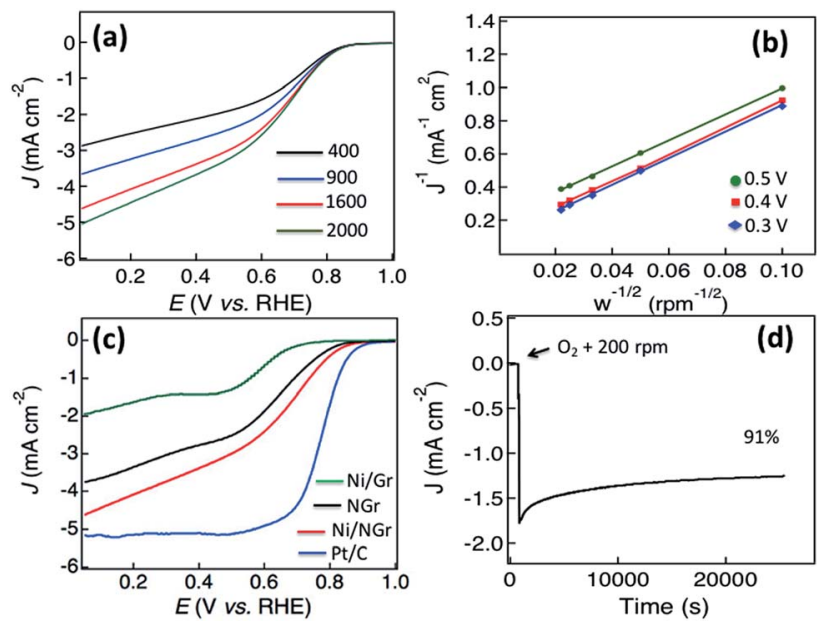

Fig. 4 (a) Linear sweep voltammograms (LSVs) of Ni/NGr at different rotation frequencies at a scan rate of $10 \mathrm{mV} \mathrm{s}^{-1}$ in $\mathrm{O}_{2}$-saturated $0.1 \mathrm{M}$ $\mathrm{KOH}(\mathrm{aq})$. (b) Koutecky-Levich plots of $\mathrm{Ni} / \mathrm{NGr}$ at electrode potentials of $0.3,0.4$ and $0.5 \mathrm{~V}$ vs. RHE. (c) Comparison of LSV plots of $\mathrm{Ni} / \mathrm{Gr}, \mathrm{NGr}$, $\mathrm{Ni} / \mathrm{NGr}$ and Pt/C at $1600 \mathrm{rpm}$. (d) Stability test of Ni/NGr in chronoamperometry for $25000 \mathrm{~s}$.

$$
\frac{1}{J}=\frac{v^{1 / 6}}{0.2 n F C_{\mathrm{o}} D_{\mathrm{o}}{ }^{2 / 3} \omega^{1 / 2}}+\frac{1}{J_{\mathrm{K}}}
$$

In the Koutecky-Levich equation, $J, J_{\mathrm{K}}$, and $J_{\mathrm{L}}$ are the measured current density, the kinetic-limiting current density and the diffusion-limiting current density, respectively; $\omega$ is the angular velocity of the disc, $n$ is the overall number of electrons transferred in the oxygen reduction, $F$ is the Faraday constant (96 $\left.485 \mathrm{C} \mathrm{mol}^{-1}\right), C_{\mathrm{o}}$ is the bulk concentration of oxygen $(1.2 \times$ $\left.10^{-6} \mathrm{~mol} \mathrm{~cm}^{-3}\right), D_{\mathrm{o}}$ is the diffusion coefficient of oxygen in $0.1 \mathrm{M} \mathrm{KOH}(\mathrm{aq})\left(1.9 \times 10^{-5} \mathrm{~cm}^{2} \mathrm{~s}^{-1}\right), v$ is the kinetic viscosity $\left(0.01 \mathrm{~cm}^{2} \mathrm{~s}^{-1}\right)$ and 0.2 is a constant that is valid when the rotation speed is expressed in rpm.

The Koutecky-Levich plots of $J^{-1}$ vs. $\omega^{-1 / 2}$ at potentials of $+0.3,+0.4$ and $+0.5 \mathrm{~V}$ on the Ni/NGr electrode (Fig. $4 \mathrm{~b}$ ) show good linearity $\left(R^{2}=0.998\right)$. The electron transfer number was $3.7-3.9$ in the potential range of 0.3 to $0.5 \mathrm{~V}$, which indicated a four-electron process as the preferred pathway. A comparison of the linear sweep voltammetry curve of Ni/NGr with those of $\mathrm{NGr}, \mathrm{Ni} / \mathrm{Gr}$ and $\mathrm{Pt} / \mathrm{C}$ (Fig. 4c) reveals the superior onset potential and current density of Ni/NGr compared to NGr and Ni/Gr. The $\mathrm{Ni} / \mathrm{Gr}$ demonstrated poor ORR activity as neither the graphene nor pure nickel nanoparticles have good ORR properties, ${ }^{20}$ but in the case of $\mathrm{Ni} / \mathrm{NGr}$, the presence and distribution of nickel nanoparticles inside the nitrogen-doped graphene layers play crucial roles in the formation of a three-dimensional structure. The half-wave potential of $\mathrm{Ni} / \mathrm{NGr}$ is found to be $0.62 \mathrm{~V}$ which is much lower than that of the benchmark $\mathrm{Pt} / \mathrm{C}(0.8 \mathrm{~V})$ but comparable with those of Ir/C (0.69) and RuO/C (0.68) (Table T1 in the ESI $\dagger)$. However the kinetic current density $\left(4.6 \mathrm{~mA} \mathrm{~cm}^{-2}\right)$ is comparatively closer to the kinetic current density of $\mathrm{Pt} / \mathrm{C}$ (5.2 $\mathrm{mA} \mathrm{cm}{ }^{-2}$ ). Even though pure nickel is not a good catalyst for the ORR, the presence of nickel oxide with highly catalytically active sites of nitrogen-doped graphene enhanced the adsorption of oxygen in the solution and thus improved the kinetic current density. ${ }^{35}$ The electrocatalytic stability of $\mathrm{Ni} / \mathrm{NGr}$ was also investigated by continuous chronoamperometric measurements at a constant potential of $+0.6 \mathrm{~V}$ (Fig. $4 \mathrm{~d}$ ). The increment of current density was observed with the addition of oxygen to the solution as well as keeping the rotation speed at $200 \mathrm{rpm}$. A constant current density curve after stabilization was observed for a long cycle time and even at $25000 \mathrm{~s}$ around $91 \%$ of its initial current density was retained.

\section{Electrocatalytic activity towards the oxygen evolution reaction} (OER)

Based on the efficient electrocatalytic OER activity of nickel nanoparticles ${ }^{26}$ and nitrogen-doped graphene, ${ }^{\mathbf{1 1}, 28}$ the OER properties of the hybrid electrode material of $\mathrm{Ni} / \mathrm{NGr}$ are investigated by sweeping the RDE potential from 1.0 to $2.0 \mathrm{~V}$. From the LSV curves of $\mathrm{Ni} / \mathrm{NGr}, \mathrm{Ru} / \mathrm{C}, \mathrm{NGr}, \mathrm{Ni} / \mathrm{Gr}$ and $\mathrm{Pt} / \mathrm{C}$ plotted in Fig. 5a, the onset potentials were measured to be $1.48,1.46,1.56,1.49$ and $1.68 \mathrm{~V}$ respectively. The potentials for a current density of $10 \mathrm{~mA} \mathrm{~cm}{ }^{-2}$ for Ni/NGr, Ru/C, NGr, Ni/Gr and $\mathrm{Pt} / \mathrm{C}$ were evaluated at 1.62, 1.64, 1.76, 1.78 and $1.88 \mathrm{~V}$ 

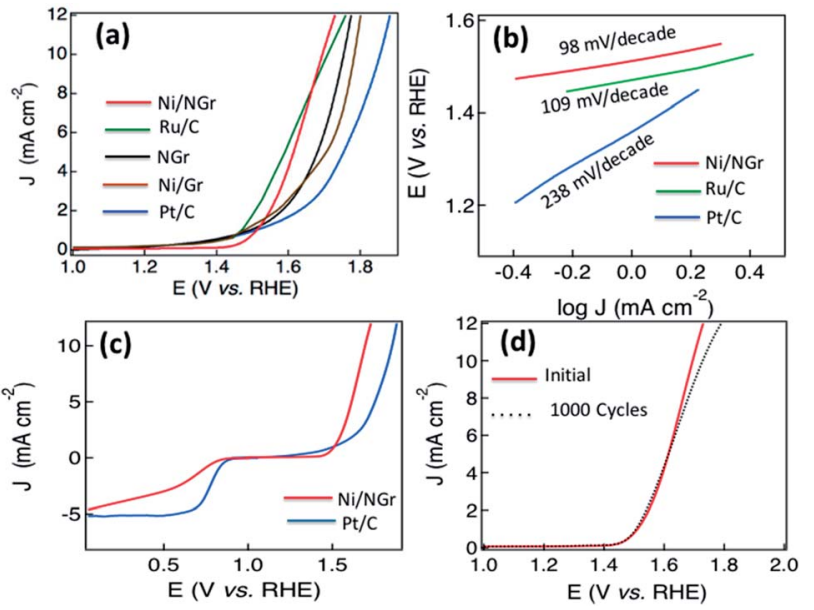

Fig. 5 (a) Linear sweep voltammograms (LSV) of Ni/NGr, Ru/C, NGr, $\mathrm{Ni} / \mathrm{Gr}$ and $\mathrm{Pt} / \mathrm{C}$ at a scan rate of $10 \mathrm{mV} \mathrm{s}^{-1}$ in $0.1 \mathrm{M} \mathrm{KOH}(\mathrm{aq})$. (b) The Tafel plots of Ni/NGr, Ru/C and Pt/C. (c) LSV curves of Ni/NGr and Pt/C on an $\mathrm{RDE}(1600 \mathrm{rpm})$ in $\mathrm{O}_{2}$-saturated $0.1 \mathrm{M} \mathrm{KOH}$ (aq) at a scan rate of $10 \mathrm{mV} \mathrm{s}^{-1}$ showing the electrocatalytic activities towards both ORR and OER. (d) Comparison of LSV curves of Ni/NGr initially and after 1000 cycles for the OER.

respectively as the potential required to oxidize water at the current density of $10 \mathrm{~mA} \mathrm{~cm}{ }^{-2}$ is used to judge the OER activity. Therefore, Ni/NGr exhibited a similar onset potential and lower potential to oxidize water at the current density of $10 \mathrm{~mA} \mathrm{~cm}^{-2}$ compared to $\mathrm{Ru} / \mathrm{C}$ (one of the best electrocatalysts for the OER at present) and they were superior to those of Pt/C. Even though the Ni/Gr showed low onset potential the LSV curve indicated a two-step process due to the poorer electrocatalytic properties of graphene. The Tafel slopes for Ni/NGr, Ru/C and Pt/C were about 98,109 and $238 \mathrm{mV}$ per decade respectively indicating the better OER activity of Ni/NGr (Fig. 5b). The high exchange current density and smaller Tafel slope indicated that the OER facilitated a kinetically more efficient pathway compared to $\mathrm{RuO} / \mathrm{C}$ and Pt/C. The high distribution of nickel nanoparticles along with the high atomic percentage of nitrogen including a high percentage of pyridinic $\mathrm{N}$ and graphitic $\mathrm{N}$ on the edges of the surface creates active sites for efficient bi-catalysis reaction for oxygen reduction and evolution. The atomic doping of nickel with the configurations of $\mathrm{NiO}, \mathrm{NiOOH}$ and $\beta-\mathrm{Ni}(\mathrm{OH})_{2}$ played a crucial role to enhance the intrinsic catalytic activity of the composite. $^{36,37}$ Upon comparison of bifunctional electrocatalysis with $\mathrm{Pt} / \mathrm{C}$ measured using LSV plots obtained at $1600 \mathrm{rpm}$ in oxygen-saturated $0.1 \mathrm{M} \mathrm{KOH}$ (Fig. 5c), a comparable ORR with a four electron transfer pathway and better OER activity of $\mathrm{Ni} / \mathrm{NGr}$ were observed. In the ORR, the onset potential and current density of $\mathrm{Ni} / \mathrm{NGr}$ were lower than those of commercial $\mathrm{Pt} / \mathrm{C}$ as it is the state-of-the-art ORR electrode; however in the OER the good catalytic activity of Ni/NGr was revealed by its lower onset potential and higher current density than $\mathrm{Pt} / \mathrm{C}$.

The OER and ORR activities of $\mathrm{Ni} / \mathrm{NGr}$ are also superior to those of $\mathrm{Ru} / \mathrm{C}$, as the ORR activity of $\mathrm{Ru} / \mathrm{C}$ is poor compared to that of $\mathrm{Pt} / \mathrm{C}$ and nitrogen-doped carbons. ${ }^{15}$ The electrocatalytic stability of $\mathrm{Ni} / \mathrm{NGr}$ for the OER is also evaluated and almost similar properties are observed after 1000 cycles (Fig. 5d). Thus this active material can be a potential platform for developing bifunctional electrocatalysts for metal-air batteries and water splitting.

\section{Electrocatalytic activity towards the hydrogen evolution reaction (HER)}

After observing the efficient ORR and OER electrocatalytic properties of $\mathrm{Ni} / \mathrm{NGr}$, the electrodes were assessed in nitrogensaturated $0.1 \mathrm{M} \mathrm{KOH}$ electrolyte using a typical three-electrode cell at room temperature to evaluate the hydrogen evolution reaction (HER) properties. NGr, Ni/Gr and Pt/C catalysts with the same mass loading on a glassy carbon electrode were examined for comparison. The linear sweep voltammetry curves of Ni/NGr, NGr, Ni/Gr and Pt/C (Fig. 6a) at a scan rate of $5 \mathrm{mV}$ $\mathrm{s}^{-1}$ in $0.1 \mathrm{M} \mathrm{KOH}$ solution demonstrated electrocatalytic activity towards the HER.

Commercial Pt/C shows the best HER activity and Ni/NGr shows comparable HER activity close to that of Pt/C (Fig. 6a) in alkali medium. NGr shows poor activity toward the HER. Ni/ Gr showed better HER electrocatalysis activity for water splitting compared to $\mathrm{NGr}$ as the $\mathrm{Ni} / \mathrm{NiO}$ interface exhibits efficient hydrogen evolution electrocatalysis. ${ }^{38}$ The superior activities of $\mathrm{Ni} / \mathrm{NGr}$ indicate that the active sites in $\mathrm{Ni} / \mathrm{NiO} / \mathrm{NGr}$ are associated with $\mathrm{Ni}, \mathrm{NiO}$ and $\mathrm{N}$. The nitrogen doping influences the HER activity of the Ni/NiO nano-interface for enhanced electrocatalysis. The HER activity of the electrodes was also investigated in acidic $0.1 \mathrm{M} \mathrm{H}_{2} \mathrm{SO}_{4}$ electrolyte (Fig. 6b) and the electrodes were found to be more active in acidic media. The potential for generating a current density of $-20 \mathrm{~mA} \mathrm{~cm}{ }^{-2}$ for $\mathrm{Ni} / \mathrm{NGr}$ is $-0.18 \mathrm{~V} v s$. RHE which is superior to that reported for Co-NG. ${ }^{17}$ The Tafel plots in alkali medium show a Tafel slope of
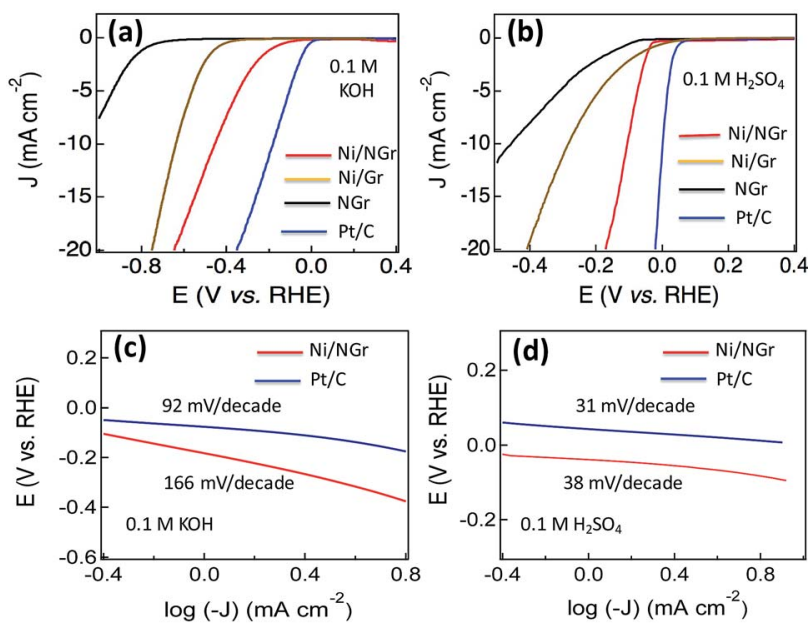

Fig. 6 (a) Linear sweep voltammograms (LSVs) of Ni/NGr, NGr, Ni/Gr and $\mathrm{Pt} / \mathrm{C}$ at a scan rate of $5 \mathrm{mV} \mathrm{s}^{-1}$ in argon-saturated $0.1 \mathrm{M} \mathrm{KOH}(\mathrm{aq})$. (b) LSV curves of Ni/NGr, NGr, Ni/Gr and Pt/C at a scan rate of $5 \mathrm{mV} \mathrm{s}^{-1}$ in argon-saturated $0.1 \mathrm{M} \mathrm{H}_{2} \mathrm{SO}_{4}$ (aq). (c) The Tafel plots of Ni/NGr and $\mathrm{Pt} / \mathrm{C}$ in $0.1 \mathrm{M} \mathrm{KOH}(\mathrm{aq})$. (d) The Tafel plots of Ni/NGr and Pt/C in $0.1 \mathrm{M}$ $\mathrm{H}_{2} \mathrm{SO}_{4}(\mathrm{aq})$. 
$166 \mathrm{mV}$ per decade for $\mathrm{Ni} / \mathrm{NGr}$ and $92 \mathrm{mV}$ per decade for $\mathrm{Pt} / \mathrm{C}$ (Fig. 6c) but in the acidic medium the Tafel plot of Ni/NGr is $38 \mathrm{mV}$ per decade close to $\mathrm{Pt} / \mathrm{C}$ ( $32 \mathrm{mV}$ per decade) (Fig. $6 \mathrm{~d}$ ). The small Tafel slope of Ni/NGr showed its efficiency of hydrogen evolution in acidic media by the active electrocatalytic nano7 interface of metal/nitrogen-doped graphene. The interaction of nitrogen with nickel and the presence of nickel oxide, the N$\mathrm{Gr} / \mathrm{Ni} / \mathrm{NiO}$ nano-interface might be the synergistically active sites for HER catalysis both in the acidic and alkaline media. In alkaline media, the HER pathway could be through the VolmerHeyrovsky process or Volmer-Tafel pathways. ${ }^{24}$

$$
\begin{aligned}
& \mathrm{H}_{2} \mathrm{O}+\mathrm{e}^{-} \rightarrow \mathrm{H}_{\mathrm{ads}}+\mathrm{OH}^{-} \text {(Volmer) and } \\
& \mathrm{H}_{\mathrm{ads}}+\mathrm{H}_{\mathrm{ads}} \rightarrow \mathrm{H}_{2} \text { (Tafel) }
\end{aligned}
$$

$$
\begin{aligned}
& \mathrm{H}_{2} \mathrm{O}+\mathrm{e}^{-} \rightarrow \mathrm{H}_{\mathrm{ads}}+\mathrm{OH}^{-} \text {(Volmer) and } \\
& \mathrm{H}_{2} \mathrm{O}+\mathrm{H}_{\mathrm{ads}}+\mathrm{e}^{-} \rightarrow \mathrm{H}_{2}+\mathrm{OH}^{-} \text {(Heyrovsky) }
\end{aligned}
$$

Both pathways involve the adsorption of an $\mathrm{H}_{2} \mathrm{O}$ molecule, electrochemical reduction of the adsorbed $\mathrm{H}_{2} \mathrm{O}$ into adsorbed $\mathrm{OH}^{-}$and a $\mathrm{H}$ atom, desorption of $\mathrm{OH}^{-}$to refresh the surface and formation of a $\mathrm{H}$ adsorbed intermediate for $\mathrm{H}_{2}$ generation. The $\mathrm{H}$ atom binding energy of $\mathrm{Ni}$ metal is close to that of Pt; however the HER catalytic activity is worse compared with Pt. ${ }^{26}$ The exact nature of the HER of nickel/nickel oxide on nitrogendoped graphene is still unknown. Therefore, we assume that the nature would be similar to the proposed mechanism for heterostructured $\mathrm{NiO} / \mathrm{Ni}$ hybrid as $\mathrm{OH}^{-}$generated by $\mathrm{H}_{2} \mathrm{O}$ splitting could preferentially attach to the nitrogen-doped graphene/NiO site at the interface due to strong electrostatic affinity to the locally positively charged $\mathrm{Ni}^{2+}$ species and more unfilled $\mathrm{d}$ orbitals in $\mathrm{Ni}^{2+}$ than in Ni metal, while a nearby Ni site would facilitate $\mathrm{H}$ adsorption and thus the Volmer process, imparting synergistic HER catalytic activity to Ni/NiO-NGr. ${ }^{24}$

\section{Electrocatalytic activity towards the hydrogen peroxide oxidation reaction (HPOR)}

The recent attention on developing hydrogen peroxide fuel cells, hydroxide exchange membrane fuel cells and fuel cells for outer space and underwater applications requires efficient noble metal free electrodes for the hydrogen peroxide oxidation reaction (HPOR). ${ }^{39,40}$ Due to the multifunctional roles of hydrogen peroxide in fuel cells as a liquid oxidant, fuel for onecompartment or membraneless fuel cells, source of oxygen in an air-free environment and for avoiding water flooding, the importance of the use of hydrogen peroxide for developing advanced fuel cells is highly crucial, and thus the development of efficient noble-metal free electrocatalysts. ${ }^{40-42}$ Nickel supported nitrogen-doped carbon nanotubes and nickel deposited carbon fiber had been demonstrated to exhibit promising electrocatalytic properties for hydrogen peroxide oxidation reaction (HPOR) activity respectively. ${ }^{23,43}$ Observing the HPOR activity of nickel deposited carbon material, the HPOR activity of the synthesized Ni/NGr is also explored. The cyclic voltammograms of $\mathrm{Ni} / \mathrm{NGr}$ in argon saturated $0.1 \mathrm{M} \mathrm{NaOH}$ solution without adding any hydrogen peroxide showed a linear feature without any oxidation or reduction peak, and a broad electrooxidation peak of hydrogen peroxide at around $0.96 \mathrm{~V}$ associated with a small hydrogen peroxide reduction peak at $0.85 \mathrm{~V}$ was observed after adding $0.5 \mathrm{mM}$ solution of hydrogen peroxide (Fig. 7a).

Linear sweep voltammetry was applied to investigate the effects of current density with the raising of concentration at a rotation frequency of $1600 \mathrm{rpm}$. The increment of current density for the HPOR as well as hydrogen peroxide reduction reaction (HPRR) was observed with the increment of concentration (Fig. 7b). The adsorption of the oxygen generated in the HPOR process and the peroxide ions on the transition metal/ metal oxide surface was attributed to the high current density. ${ }^{39}$ Increments of current were also observed in Fig. $7 \mathrm{c}$ with the increments of rotation frequency in the solution of $0.1 \mathrm{M} \mathrm{NaOH}$ with $4 \mathrm{mM} \mathrm{H}_{2} \mathrm{O}_{2}$. In alkaline media, the HPOR takes place to form oxygen, water and electrons according to the following mechanism, ${ }^{40}$

$$
\mathrm{HO}_{2}^{-}+\mathrm{OH}^{-} \rightarrow \mathrm{O}_{2}+\mathrm{H}_{2} \mathrm{O}+2 \mathrm{e}^{-}
$$

In addition, the HPRR takes place in alkaline media according to

$$
\mathrm{O}_{2}+2 \mathrm{H}_{2} \mathrm{O}+4 \mathrm{e}^{-} \rightarrow 4 \mathrm{OH}^{-}
$$

The comparison of Ni/NGr with $\mathrm{Ni} / \mathrm{Gr}$ and $\mathrm{Pt} / \mathrm{C}$ for the HPOR and HPRR in Fig. $7 d$ indicates the superior current density of $\mathrm{Ni} / \mathrm{NGr}$ than Pt/C at a rotation frequency of $1600 \mathrm{rpm}$ in argon saturated $0.1 \mathrm{M} \mathrm{NaOH}$ solution with $4 \mathrm{mM} \mathrm{H}_{2} \mathrm{O}_{2}$. The Ni/Gr exhibits comparatively poor HOR and HPRR activity due to the poor electrocatalytic properties of graphene. The high current density observed for the HPRR at lower potential is due
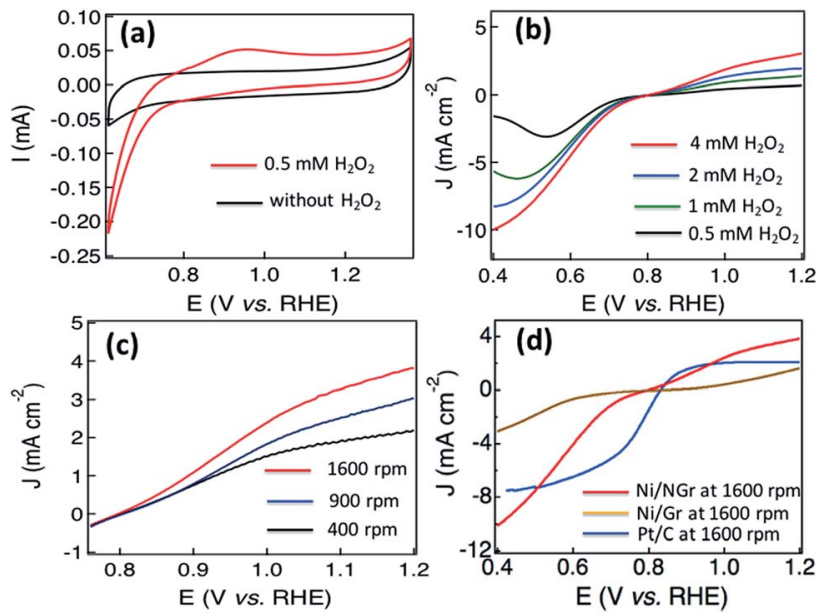

Fig. 7 (a) Cyclic voltammograms (CV) of Ni/NGr in argon-saturated $0.1 \mathrm{M} \mathrm{NaOH}(\mathrm{aq})$ in the absence and presence of $\mathrm{H}_{2} \mathrm{O}_{2}$, (b) LSV curves of $\mathrm{Ni} / \mathrm{NGr}$ at a scan rate of $5 \mathrm{mV} \mathrm{s}^{-1}$ in argon-saturated $0.1 \mathrm{M} \mathrm{NaOH}$ (aq) with different concentrations of $\mathrm{H}_{2} \mathrm{O}_{2}$, (c) the LSV curves of Ni/NGr at different rotation frequencies at a scan rate of $5 \mathrm{mV} \mathrm{s}^{-1}$ in argonsaturated $0.1 \mathrm{M} \mathrm{NaOH}(\mathrm{aq})$ with $4 \mathrm{mM} \mathrm{H}_{2} \mathrm{O}_{2}$, (d) LSV curves of $\mathrm{Ni} / \mathrm{NGr}$ and $\mathrm{Pt} / \mathrm{C}$ on an RDE (1600 rpm) in argon-saturated $0.1 \mathrm{M} \mathrm{NaOH}(\mathrm{aq})$ with $4 \mathrm{mM} \mathrm{H}_{2} \mathrm{O}_{2}$ at a scan rate of $5 \mathrm{mV} \mathrm{s}^{-1}$ showing electrocatalytic activities towards both HPOR and HPRR. 
to the lower activation energy of the hydrogen peroxide reduction reaction compared to the oxygen reduction reaction of oxygen molecules. The fast kinetics and large current density of the hydrogen peroxide reduction reaction might be associated with the comparatively lower energy required for breaking the single oxygen bond $\left(146 \mathrm{~kJ} \mathrm{~mol}^{-1}\right)$ in hydrogen peroxide than the double oxygen bond $\left(494 \mathrm{~kJ} \mathrm{~mol}^{-1}\right)$ in oxygen molecules. ${ }^{44}$ Thus the nanostructured Ni/NGr shows remarkable electrocatalytic activity for the HPOR associated with the HPRR in hydrogen peroxide and can be a promising electrode for the development of reversible and one compartment hydrogen peroxide based fuel cells.

\section{Conclusions}

In conclusion, we report a single pot synthesis of nickel and nickel oxide embedded $\mathrm{N}$-doped graphenes $(\mathrm{Ni} / \mathrm{NGr}$ ) with high electrocatalytic activity. The superior electrochemical activities for the ORR, OER, HER and HPOR are attributed to the synergistic effect of the high atomic percentage of nitrogen including edge $\mathrm{N}$ atoms and $\mathrm{Ni}$. The efficient atomic percentage of nickel doping on the carbon lattice of graphene contributes to single atom catalysis along with the embedded nickel/nickel oxide nanoparticles on the nitrogen-doped graphene surface. The quadrafunctional electrocatalytic activities of the composite for the ORR, OER, HER and HPOR demonstrate the applicability of this nanostructured electrode material for developing multifunctional energy storage and conversion devices such as reversible fuel cells, metal-air batteries, hybrid energy storage systems, platinum-free electrolyzers for complete water splitting and hydrogen peroxide based one compartment fuel cells.

\section{Conflicts of interest}

There are no conflicts to declare.

\section{Acknowledgements}

S. N. Faisal and E. Haque are grateful to the University of Sydney for USydIS postgraduate scholarships. N. Noorbehesht gratefully acknowledges financial support in the form of a Postgraduate Scholarship from the CSIRO-National Research Flagships Program (Future Manufacturing Flagship; No. FlagshipPhD12/03743). ATH and AIM are thankful for the ongoing support of the ARC and University of Sydney.

\section{Notes and references}

1 A. S. Arico, P. Bruce, B. Scrosati, J. M. Tarascon and W. V. Schalkwijk, Nat. Mater., 2005, 4, 366-377.

2 J. Zhang, Z. Xia and L. Dai, Sci. Adv., 2015, 1, 15005641500583.

553 S. Zhai, H. E. Karahan, L. Wei, Q. Qian, A. T. Harris, A. I. Minett, S. Ramakrishna, A. K. Ng and Y. Chen, Energy Storage Materials, 2016, 3, 123-129.

4 S. H. Joo, S. J. Choi, I. Oh, J. Kwak, Z. Liu, O. Terasaki and R. Ryoo, Nature, 2001, 412, 169-172.
5 P. V. Kamat, J. Phys. Chem. Lett., 2012, 3, 3404.

6 Y. Hou, Z. Wen, S. Cui, S. Ci, S. Mao and J. Chen, Adv. Funct. Mater., 2015, 25, 872-882.

7 H. Liu, Y. Liu and D. Zhu, J. Mater. Chem., 2011, 21, 33353345.

8 E. Pourazadi, E. Haque, S. N. Faisal and A. T. Harris, Mater. Chem. Phys., 2018, 207, 380-388.

9 H. Wang, T. Maiyalagan and X. Wang, ACS Catal., 2012, 2, 781-794.

10 Y. Zhao, R. Nakamura, K. Kamiya, S. Nakanishi and K. Hashimoto, Nat. Commun., 2013, 4, 2391-2398.

11 Z. Lin, G. H. Waller, Y. Liu, M. Liu and C. P. Wong, Carbon, 2013, 53, 130-136.

12 R. Zhou, M. Jaroniec and S. Z. Qiao, ChemCatChem, 2015, 7, 3808-3817.

13 B. Y. Xia, Y. Yan, X. Wang and X. W. Lou, Mater. Horiz., 2014, 1, 379-399.

14 J. Zhang, Z. Zhao, Z. Xia and L. Dai, Nat. Nanotechnol., 2015, 10, 444-452.

15 R. Li, Z. Wei and X. Gou, ACS Catal., 2015, 5, 4133-4142.

16 D. Li, M. B. Muller, S. Gilje, R. B. Kaner and G. G. Wallace, Nat. Nanotechnol., 2008, 3, 101-105.

17 H. Fei, J. Dong, M. J. A. Jimenez, G. Y. N. D. Kim, E. L. G. Samuel, Z. Peng, Z. Zhu, F. Qin, J. Bao, M. J. Yacaman, P. M. Ajayan, D. Chen and J. M. Tour, Nat. Commun., 2015, 6, 8668-8676.

18 S. Guo, S. Zhang, L. Wu and S. Sun, Angew. Chem., Int. Ed., 2012, 51, 11770-11773.

19 P. Quaino, F. Juarez, E. Santos and W. Schmickler, Beilstein J. Nanotechnol., 2014, 5, 846-854.

20 X. Liu, W. Liu, M. Ko, M. Park, M. G. Kim, P. Oh, S. Chae, S. Park, A. Casimir, G. Wu and J. Cho, Adv. Funct. Mater., 2015, 25, 5799-5808.

21 J. Du, F. Cheng, S. Wang, T. Zhang and J. M. Chen, Sci. Rep., 2014, 4, 4386-4392.

22 M. M. Islam, S. N. Faisal, T. Akhter, A. K. Roy, A. I. Minett, K. Konstantinov and S. X. Dou, Part. Part. Syst. Charact., 2017, 34, 1600386(1)-1600386(6).

23 Z. Zhuang, S. A. Giles, J. Zheng, G. R. Jenness, S. Caratzoulas, D. G. Vlachos and Y. Yan, Nat. Commun., 2016, 7, 1014110148.

24 M. Gong, W. Zhou, M. C. Tsai, J. Zhou, M. Guan, M. Lin, B. Zhang, Y. Hu, D. Y. Wang, J. Yang, S. J. Pennycook, B. J. Hwang and H. Dai, Nat. Commun., 2014, 5, 4695-4701. 25 J. Ren, A. Antonietti and T. P. Fellinger, Adv. Energy Mater., 2015, 5, 1401660-1401666.

26 W. Sheng, M. Myint, J. G. Chen and J. Y. Yan, Energy Environ. Sci., 2013, 6, 1509-1512.

27 S. Chen, J. Duan, J. Ran, M. Jaroniec and S. Z. Qiao, Energy Environ. Sci., 2013, 6, 3693-3699.

28 S. N. Faisal, E. Haque, N. Noorbehesht, W. Zhang, A. T. Harris, T. L. Church and A. I. Minett, RSC Adv., 2017, 7, 17950-17958.

29 Y. Zhu, W. Chu, N. Wang, T. Lin, W. Yang, J. Wen and X. S. Zhao, RSC Adv., 2015, 5, 77958-77964.

30 A. Kamyabi-Gol, S. M. Zebarjad and S. A. Sajjadi, Colloids Surf., A, 2009, 336, 69-74. 
31 J. Wang, Z. Wei, S. Mao, H. Li and Y. Wang, Energy Environ. Sci., 2018, 11, 800-806.

32 M. R. Salvadori, C. A. O. Nascimento and B. Corrêa, Sci. Rep., 2014, 4, 6404(1)-6404(6).

33 N. Weidler, J. Schuch, F. Knaus, P. Stenner, S. hoch, A. Maljusch, R. Schäfer, B. Kaiser and W. Jaegermann, $J$. Phys. Chem. C, 2017, 121, 6455-6463.

34 P. Ganesan, A. Sivanantham and S. Shanmugam, J. Mater. Chem. A, 2016, 4, 16394-16402.

35 V. Vij, S. Sultan, A. H. Harzandi, A. Meena, J. N. Tiwari, W. G. Lee, T. Yoon and K. S. Kim, ACS Catal., 2017, 7, 7196-7225.

36 B. Kim, A. Oh, M. K. Kabiraz, Y. Hong, J. Joo, H. Baik, S. Choi and K. Lee, ACS Appl. Mater. Interfaces, 2018, 10, 1011510122 .
37 T. Zhou, Z. Cao, P. Zhang, H. Ma, Z. Gao, H. Wang, Y. Lu, J. He and Y. Zhao, Sci. Rep., 2017, 7, 46154(1)-46154(10).

38 Z. Zhang, S. Liu, F. Xiao and S. Wang, ACS Sustainable Chem. Eng., 2017, 5(1), 529-536.

39 T. Poux, A. Bnnefont, A. Ryabova, G. Kéranguéven, G. A. Tsirlina and E. R. Savinova, Phys. Chem. Chem. Phys., 2014, 16, 13595-13600.

40 L. An, T. Zhao, X. Yan, Z. Zhou and P. Tan, Sci. Bull., 2015, 60, 55-64.

41 Y. Yamada, M. Yoneda and S. Fukuzumi, Energy Environ. Sci., 2015, 8, 1698-1701.

42 A. E. Sanli, Int. J. Energy Res., 2013, 7, 1488-1497.

43 A. Aytac, M. Gurbuz and A. E. Sanli, Int. J. Hydrogen Energy, 2011, 36, 10013-10021.

44 D. Cao, L. Sun, G. Wang, Y. Lv and M. Zhang, J. Electroanal. Chem., 2008, 621, 31-37. 